\title{
State of art of bus rapid transit transportation
}

\author{
Elvira Maeso-González • Pablo Pérez-Cerón
}

Received: 8 October 2012 / Accepted: 15 July 2013 /Published online: 15 September 2013

(C) The Author(s) 2013. This article is published with open access at SpringerLink.com

\begin{abstract}
Purpose The increasing importance of the Bus Rapid Transit systems in the last 20 years has given rise to the implementation of several sorts of systems over the world with different characteristics and success levels.

This paper aims to describe a global approach of them as well as to carry out an effective comparison in order to achieve outstanding conclusions.

Methods From the conceptualization or determination of the main features and evolution of BRT Systems we do a qualitative and quantitative analysis of the currently operating systems according to the development of countries in which they operate in order to identify the key factors for the success of such type of transportation, regarding both its management and users comfort.

Results and conclusions Comparison between different BRT systems according to their geographical area provides some important evidences. Paper results suggest that we can find two separate groups in BRT systems, on one hand, some countries with more technology and commercial velocity (European, Australian and Americans BRT systems), and on the other hand countries more developed in terms of service, ridership, routes and impact in population. It's necessary to understand the BRT in the context of the mobility of the city and as long as this system has to compete with other modes of transport the compliance of desirable requirements for a full BRT become more essential.
\end{abstract}

\footnotetext{
E. Maeso-González $(\bowtie) \cdot$ P. Pérez-Cerón

Cátedra de Gestión del Transporte, University of Málaga, Estación de autobuses. Paseo de los Tilos s/n, 29006 Málaga, Spain

e-mail: cgtransporte@uma.es

E. Maeso-González

e-mail: emaeso@uma.es

P. Pérez-Cerón

e-mail: pablopceron@gmail.com
}

Keywords Bus rapid transit · State of art · Characteristics · Public transport $\cdot$ Comparative

\section{Introduction}

There are many definitions for the Bus Rapid Transit (BRT) system. According to Thomas [1], it is a "rapid mode of transportation that can combine the quality of rail transit and the flexibility of buses", while Levinson et al. [2] give more technical details "a flexible, rubber-tired rapid transit mode that combine stations, vehicles, services, running way, and ITS elements into an integrated system with a strong positive image and identity". Wright focuses on the economic aspect "BRT is high-quality, customer-orientated transit that delivers fast, comfortable and cost-effective urban mobility" and the IDTP [3] includes the use of segregated lanes "a high-quality bus based transit system that delivers fast, comfortable, and cost-effective urban mobility through the provision of segregated right-of-way infrastructure, rapid and frequent operations, and excellence in marketing and customer service".

As a result of the above information, we can define a BRT system at present as a collective way of land transportation based on the functional features of LRT (Light Rail Transit) that benefits from the economic advantages and flexibility of the bus, so it can offer a collective service of land transportation in a comfortable, fast and functional way by rubber-tired vehicles. It implies an important decrease of costs compared to other ways of service at the same level.

The main difference between BRT and urban railway systems is that the BRT can provide with services of high quality massive transportation at a very lower cost, whose price for the city could be between 4 and 20 times less than a LRT system and between 10 and 100 times less than an underground type system (GTZ, [4]).

BRT systems are seen by local governments as an interesting transportation option, according to Kittelson and Levinson 
[5], due to several features such as the appropriate design of vehicles, the fast way of validation of the Intelligent Transportation Systems (ITS), the availability of right-of-way roadways which afford a high frequent service during the whole day, the possibility of operating in all kind of road (even in the historic district), their ability to be built quickly and gradually or to join easily other transportation systems both local and express, as well as their low implantation cost compared to the train or underground, while their benefits would be similar. In addition, as shown in some publications (Mojica C. and Rodríguez D. [6]; Muñoz-Raskin, [7]), the implementation of a BRT in cities leads to an increasing of the value of properties and market surrounding the areas in which it operates, so it contributes to the regeneration and promotion of highly populated areas.

The possibility of being incrementally developed and the flexibility to operate are just exclusive advantages of the BRT against LRT or any other transportation system nowadays. First of all, an incremental development allows the implementation of the system in different phases, so that the investment cost derived both from the construction of stations and lines and the maintenance can be distributed in time. Since the implementation will be gradual, it is important at the beginning to choose a set of attractive conditions to demonstrate the advantages of the BRT system and help the investment in infrastructures and future extensions or improvement works in the line.

On the other hand, the rapid transit systems offer a flexibility to operate which can be observed in different features. Regarding the routes, it is important to underline that the buses can generally run on all kind of roadways, even on the roads in the centre of the towns, which can be considered narrower than usual. Also, they allow the use of vehicles with higher or lower capacity depending on the needs of the service, so they can operate with articulated, standard or small buses, according to the quantity of users of a line, and change such configuration if the evolution of demand shows a change of the needs over time. Moreover, alternative routes could be adopted in case of eventual works or accidents on the road.

However, BRT systems have also some disadvantages compared to other ways of public transportation. Buses have usually less capacity than LRT systems or underground, what must be taken into account to plan the routes. Besides, according to the right-of-way level of the roadway, there may be non-exclusive lanes for buses. Finally, BRT will be always slower than the underground, because of the shorter distance between the stops for the first one and the established proceedings to be followed in crossroads.

At this point we wonder whether BRT systems currently in the world will have all these features we have seen. And if it's not the case, the extent to which a larger number of lines, exclusive line, priority in crossroads, velocity, system identity, etc. will be critical to the successful implementation of BRT in a city.

\section{History of the BRT systems}

The current BRT system was suggested for the first time in Chicago in 1937, when three rail lines were converted to superhighways of buses. Nevertheless, the total implementation of measures to give priority to buses took place in 1963 in the metropolitan area of New York. One year later, they started operating in Paris and then, in 1966, the first exclusive lanes were created in St. Louis (USA) and Liege (Belgium) in the centre of the road. In South America, the first exclusive lane arrived in 1972 to Lima (Peru).

Nevertheless, the full idea of BRT appeared with the "land tube" in Curitiba (Brazil) in 1973. The city was looking for a rail-leading system, but the lack of investment made it in a more creative way and with alternative measures, by developing lanes exclusive for buses leaving from the city centre. With its new transportation system, whose stations in a tube form and articulated buses represent a worldwide example, the city started a development which continues today. The BRT system has now six radial right-of-ways connecting the city centre to districts. Then, other Brazilian cities have followed this model with basic systems developed in São Paulo (1975), Goiânia (1976), Porto Alegre (1977), Belo Horizonte (1981) (Meirelles [8]).

Despite the success in Curitiba, the extension of BRT stopped due to the oil crisis in the decade of 1980, when we could only mention as a positive aspect the creation of the "mechanically guided busways" in Essen (Germany) and other European cities, although this new concept of rail guided wheels was not widely accepted. Then, in the decade of 1990 , BRT systems started to be considered as a less attractive alternative than railway, often used in small cities or with low budget. But the appearing of TransMillenio system in Bogota, with a population of more than 7 million people and a density of 240 inhabitants per ha, demonstrated again that BRT can serve a high capacity performance in the largest cities of the world.

Table 1 Qualitative analysis

\begin{tabular}{lll}
\hline Feature & Percentage & Observations \\
\hline Exclusive lane & 100.00 & \\
Priority in crossroads & 62.50 & \\
Outdoor ticket sale & 64.58 & \\
Level boarding & 68.75 & over 45 cities \\
Low emission technologies & 77.78 & \\
$\quad$ Euro 3 or improved) & 85.42 & over 37 cities \\
Information in real time & 62.16 & \\
Intermodal stations & 91.67 & \\
System identity and image & 37.50 & \\
Non-exclusive stretches &
\end{tabular}

Own compilation 
Table 2 Quantitative analysis in areas

\begin{tabular}{lllllllll}
\hline$\%$ & $\begin{array}{l}\text { EXCL } \\
\text { LANE }\end{array}$ & $\begin{array}{l}\text { PRIO } \\
\text { CROSSR }\end{array}$ & $\begin{array}{l}\text { EXTERN } \\
\text { SALE }\end{array}$ & $\begin{array}{l}\text { LEVEL } \\
\text { BOARDING }\end{array}$ & $\begin{array}{l}\text { LOW } \\
\text { EMISS }\end{array}$ & $\begin{array}{l}\text { INFO REAL } \\
\text { TIME }\end{array}$ & $\begin{array}{l}\text { INTERMO } \\
\text { STATIONS }\end{array}$ & $\begin{array}{l}\text { IDENTITY \& } \\
\text { IMAGE }\end{array}$ \\
\hline EUROPE & 100 & 100 & 14 & 100 & 100 & 100 & 100 & 86 \\
AFRICA & 100 & 100 & 100 & 0 & 50 & 50 & 50 & 100 \\
ASIA & 100 & 42 & 79 & 79 & 94 & 79 & 44 & 89 \\
NORTH AMERICA & 100 & 100 & 33 & 17 & 100 & 50 & 78 & 30 \\
SOUTH AMERICA & 100 & 30 & 90 & 100 & 100 & 100 & 100 & 90 \\
OCEANIA & 100 & 100 & 25 & 0 & & & 100 \\
\hline
\end{tabular}

Own compilation

TransMillenio started operating in 2000 and in 2006 had already reached $84 \mathrm{~km}$ of exclusive lanes. Nowadays, it can take 1.6 million of passenger daily. The experience in Curitiba has directly influenced the development of BRT initiatives in other cities such as Seul (2004) and Beijing (2005).

BRT systems implemented in different cities of the world, such as Curitiba and Bogota, are currently almost a hundred, without taking into account those in development phases.

Table 3 Quantitative analysis

\begin{tabular}{|c|c|c|c|c|}
\hline FEATURE & Quantity & & $\begin{array}{l}\text { Standard } \\
\text { deviation }\end{array}$ & $\mathrm{CV}$ \\
\hline $\begin{array}{l}\text { Average length of exclusive } \\
\text { lanes }(\mathrm{km})\end{array}$ & 29.52 & & 24.97 & 0.85 \\
\hline $\begin{array}{l}\text { Average length of nonexclusive } \\
\text { lanes }(\mathrm{km})\end{array}$ & 13.13 & & 13.53 & 1.03 \\
\hline Total average length $(\mathrm{km})$ & 42.65 & & 8.08 & 0.19 \\
\hline $\begin{array}{l}\text { Average distance amongst } \\
\text { stations }(\mathrm{m})\end{array}$ & 781 & & 323.28 & 0.41 \\
\hline Number of lines & 4 & & 3.10 & 0.80 \\
\hline Number of trips per day & 213,205 & & 345,295 & 1.62 \\
\hline Average price (\$) & 0.92 & & 0.89 & 0.97 \\
\hline Average price in Africa $(\$)$ & 2.08 & & & \\
\hline Average price in Asia (\$) & 0.32 & & & \\
\hline Average price in Europe $(\$)$ & 1.89 & & & \\
\hline $\begin{array}{l}\text { Average price in North America } \\
\text { (S) }\end{array}$ & 1.44 & & & \\
\hline Average price in Oceania (\$) & 2.27 & & & \\
\hline $\begin{array}{l}\text { Average price in South America } \\
\text { (\$) }\end{array}$ & 0.52 & & & \\
\hline Average peak velocity $(\mathrm{km} / \mathrm{h})$ & 23.95 & & 11.23 & 0.47 \\
\hline $\begin{array}{l}\text { Average cost of infrastructures } \\
(\mathrm{M} \$ / \mathrm{km})\end{array}$ & 6.44 & & 8.64 & 1.34 \\
\hline \multirow[t]{4}{*}{ Most common propulsion } & Diesel & 76.09 & & \\
\hline & GNC & 23.91 & & \\
\hline & Hybrid & 6.52 & & \\
\hline & GLP & 2.17 & & \\
\hline
\end{tabular}

Own compilation

\section{Comparative amongst BRT current systems}

In this section we will show the results of the study carried out to compare the different BRT operating systems nowadays; they will allow us to assess the main features needed for their implementation and correct performance.

With this aim, we have elaborated a global comparative of 48 systems as independent and then we will also accomplish an analysis of them in groups, regarding their countries.

For carrying out such analysis, we have extracted information from the China BRT Database [9], Bus Rapid Transit Policy Center [10] and the Institute for Transportation and Development Policy [3].

To begin with, we have crossed all the data in order to determinate the most common features of a Bus Rapid Transit system. The results of such compendium are shown in Table 1 .

As it can be observed, it is essential for every BRT system the existence of exclusive lanes. Several cities have also some of the lanes whose use is non-exclusive for BRT, but all of them have routes only for buses. Then, we find that an identity and image for the system is quite important in a $91.67 \%$ of the cases, and the use of ITS systems to give information in real time to users (for example, the waiting time for the next vehicle) is also very appreciated. Finally, the fourth feature would be the use of low emission fuel, usually Diesel Euro 3 and sometimes improved.

According to the percentages, we confirm that BRT systems offer a quick transportation option, modern and suitable for the needs of users, and that they have a good external image (thanks to their own identity and the low emission technology).

We can also consider such features according to geographical areas. The results are in Table 2.

Hensher y Golob [11] concluded, according to the data from Wright y Hook [3], that European and South American systems were remarkable for the level boarding, while the South American was especially effective in the elimination of priority in crossroads (that is, it was the area with the least systems of priority in crossroads, but it didn't affect the traffic) 
Table 4 Quantitative analysis per continents

\begin{tabular}{|c|c|c|c|c|c|c|}
\hline FEATURE & AFRICA & SOUTH AMERICA & ASIA & USA CANADA & EUROPE & OCEANIA \\
\hline Length of exclusive lanes (km) & 58.00 & 38.50 & 32.08 & 23.27 & 16.67 & 12.50 \\
\hline length of nonexclusive lanes $(\mathrm{km})$ & 0.00 & 2.00 & 7.24 & 2.67 & 6.11 & 5.00 \\
\hline Total length of lanes $(\mathrm{km})$ & 58.00 & 40.50 & 39.32 & 25.94 & 22.79 & 17.50 \\
\hline Number of stations & 88 & 69 & 46 & 19 & 34 & 19 \\
\hline Average distance between stations (m) & 500 & 558 & 907 & 883 & 679 & 1959 \\
\hline Number of lines & 6 & 5 & 5 & 2 & 2 & 2 \\
\hline Number of trips per day & 151,500 & 496,900 & 227,231 & 43,383 & 39,786 & 47,450 \\
\hline Inhabitants city (people) & 5912,500 & 3745,400 & 4962,474 & 1024,000 & 630,429 & 2013,500 \\
\hline Average price $(\$)$ & 2.08 & 0.52 & 0.33 & 1.44 & 2 & 2.27 \\
\hline Peak hour velocity $(\mathrm{km} / \mathrm{h})$ & - & 19.40 & 20.84 & 35.38 & 22 & 46.67 \\
\hline Infrastructure cost $(\mathrm{M} \$ / \mathrm{km})$ & 7.83 & 3.48 & 5.86 & 8.75 & 6.49 & 13.07 \\
\hline
\end{tabular}

Own compilation

and Asia had the most variety of payment systems before boarding. After having studied our figures, including some additional systems, we observe that the previous conclusions continue to be fulfilled with the African systems, which couldn't be studied before, in the last place.

The next phase of our study consists of a quantitative analysis of the features of the same systems in order to observe the data about how an average BRT system would be, see Table 3 .

This way, an average BRT system would have $42 \mathrm{~km}$ of lanes of which 29.5 would be exclusive ( $70 \%$ of the course), 4 lines, and would be used by more than 213,000 passengers a day, at a price of $0.92 \$$ per trip. The costs for this system would be 6.42 million $\$$ for each $\mathrm{km}$. Besides, the buses propulsion system would be diesel fuel for most of them.

We also observe that the number of trips per day and the average infrastructure costs have the highest coefficient of variability (CV), since in both aspects there are important differences amongst the cities studied. Regarding the infrastructure, a BRT system in an Asian or South American city will be always less costly to build than in a leading European or American city.

Comparing the different systems according to their geographical area (Africa, Asia, Europe, Oceania, South America and USA-Canada) we observe that the BRT systems in North America, Oceania and Europe have the fastest BRT systems, but also the least developed, since they have less kilometres of lanes, less stations and lower quantity of lines, see Table 4.

These new data make us to separate the regions into two groups. In one group would be North America, Oceania and Europe and in the other Africa, Asia and South America. The first group has major peak hour velocity, less kilometres of lanes (about $22 \mathrm{~km}$, while the rest are much bigger), less stations ( 24 vs. 68 in the second group) and a lower quantity of lines ( 2 vs. 5). On the other hand, the African, Asian and South American systems have widely developed their
Fig. 1 Qualitative comparison per countries. Source: Own compilation according to databases

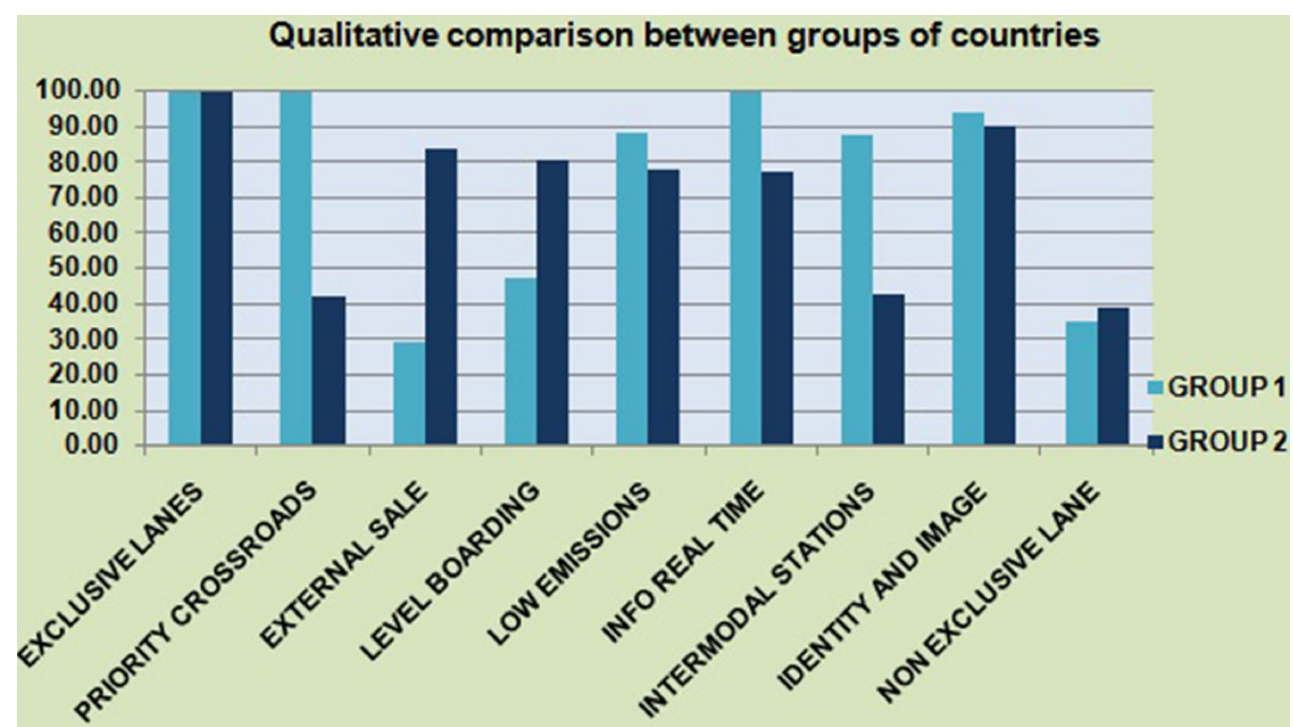


Table 5 Comparative per countries

\begin{tabular}{lll}
\hline QUALITATIVE FEATURES & Group 1 (\%) & Group 2 (\%) \\
\hline Exclusive lane & 100.00 & 100.00 \\
Priority in crossroads & 100.00 & 41.94 \\
External sale of tickets & 29.41 & 83.87 \\
Level boarding & 47.06 & 80.65 \\
Low emission technol. (Euro 3 or impr) & 88.24 & 77.78 \\
Information real time & 100.00 & 77.42 \\
Intermodal stations & 87.50 & 42.86 \\
Identity and image of the system & 94.12 & 90.32 \\
Non exclusive lanes & 35.29 & 38.71 \\
& & \\
QUANTITATIVE FEATURES & Group 1 (\%) & Group 2 (\%) \\
Length of exclusive lanes (km) & 18.02 & 35.82 \\
Length of nonexclusive lanes (km) & 13.13 & 13.13 \\
Total length of lanes(km) & 31.15 & 48.95 \\
Number of stations & 25 & 56 \\
Average distance amongst stations (m) & $1,052.41$ & 768.39 \\
Number of lines & 2 & 5 \\
Number of trips per day & 42,858 & 329,040 \\
Habitants city (people) & $1,094,764$ & $4,631,161$ \\
Average price (\$) & 1.75 & 0.51 \\
Peak hour velocity (km/h) & 32.01 & 20.34 \\
Propulsion & Diesel & Diesel \\
Cost of infrastructures (M\$/km) & 8.21 & 5.03 \\
BRT incidence in population (\%) & 3.91 & 7.10 \\
\hline & & \\
\hline
\end{tabular}

Own compilation according to databases

transportation systems with minor cost of infrastructures (in South America and Asia). If we consider the data for Africa, we must take into account that they result from the analysis of only two BRT systems (Lagos and Johannesburg) with some important differences regarding their length, stations, users and infrastructure cost. Their cost is especially variable (12.5 $\$ / \mathrm{km}$ in Lagos and $3.15 \$ / \mathrm{km}$ in Johannesburg), so we cannot conclude by saying that the African systems are more expensive to build than others or vice versa.

The explanation for these results could be based on the fact that in such geographic areas, the rapid transit systems are crucial for their public transportation system, while in more developed countries it represents only one more valid option, compared to the train or traditional lines.

With the aim of going into greater details, the following section stretches the 48 cities of our study into the two mentioned groups.

\subsection{Comparative of BRT systems per countries}

As a criterion for this study and following the mentioned differences, we have divided the countries with rapid transit buses into two groups, Group 1 (USA, Canada, and countries of Europe and Oceania) and Group 2 constituted by the countries of Asia, South America and Africa.

A variable has been created to measure the incidence of each BRT system in its city. The called incidence rate is obtained through the division of the number of trips per day between the population of the town, multiplied per 100 . The areas with a higher incidence rate will have the most consolidated BRT on the population. Then, we obtain some interesting conclusions, see Fig. 1 and Table 5.

Referring to qualitative features, the most developed countries logically have, as a consequence of the use of their resources, more complete BRT systems which can be observed in the different features: priority in crossroads, low emissions, information in real time, intermodal stations... The fact that the external
Fig. 2 Quantitative comparison (I). Source: Own compilation according to databases

\section{Quantitative comparison between groups of countries (I)}

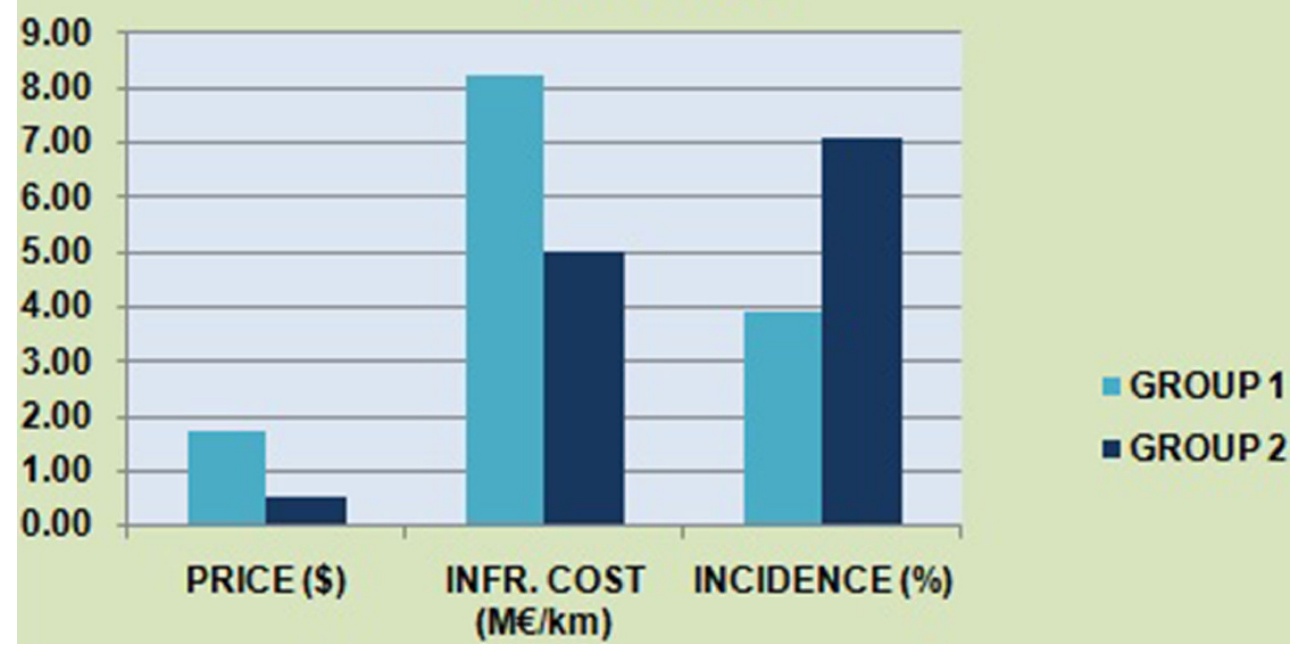


Fig. 3 Quantitative comparison (II). Source: Own compilation according to databases

\section{Quantitative comparison between groups of countries (II)}

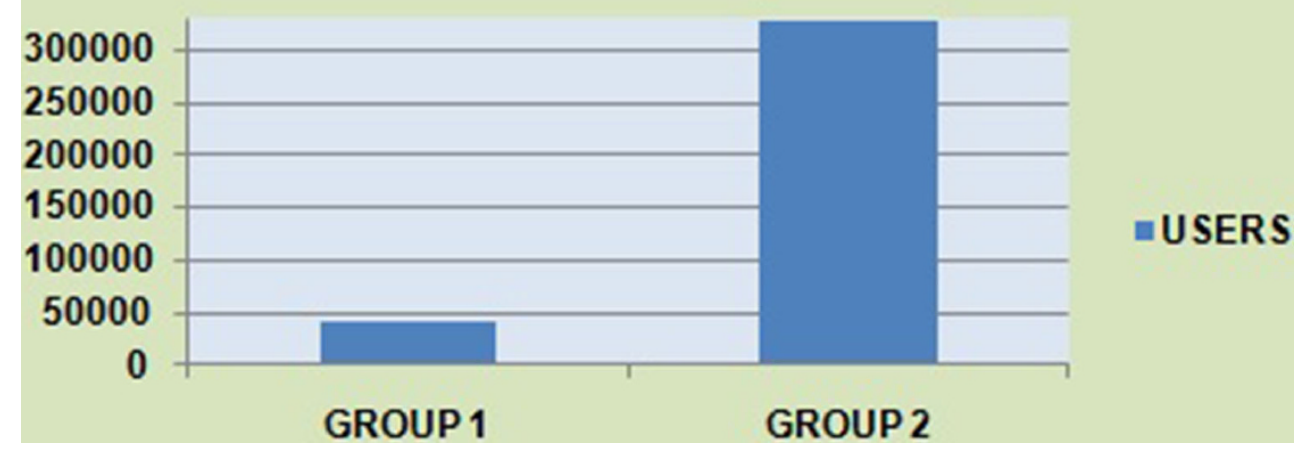

sale of tickets is quite lower in developed countries is explained due to the use of intelligent cards as their validation system inside the vehicles in Group 1. We have also observed that the identity and image for the system represent an important feature in both of the groups, whereas the priority in crossroads (one of the most important theoretical features for a BRT) is quite lower in the least developed countries.

However, quantitative features show that the least developed countries have higher figures in most of cases than the most developed. They have more kilometres of lanes, more lines, more stations and higher number of users. This is due to the fact that in such countries, BRT systems are much more consolidated as public transportation system, what is shown by the incidence rate calculated on the population. While in Group 1 countries, a BRT system is only one alternative to other ways of transport such as underground, tramway or common bus, in the least developed countries Bus Rapid Transit is clearly the most important public transportation way, because of the high quality of massive transportation at a low cost (as seen in the definition of
BRT), a cost which can be widely assumed by these cities and countries. See Figs. 2, 3 and 4.

The country which represents the best the development of BRT as an alternative to public transportation is Brazil. Rapid Transit Buses in Curitiba and Porto Alegre are respectively the first and fourth of the world according to the incidence rate calculated for the population use of BRT transportation. BRT is integrated in the city and it is the first transportation option for citizens, even more commonly used than private vehicles.

We can also compare graphically qualitative data of this ranking, in order to be able to observe how rapid transit systems of Curitiba, Ottawa and Pereira are the most important, according to their incidence. If we consider stations, kilometres of lanes, lines and number of users, BRT systems of Bogota, Curitiba and Porto Alegre again are the most popular (Fig. 5).

The high position of South America on rapid transit systems is obvious, since five of the ten systems with the greatest incidence rates are from there.
Fig. 4 Quantitative comparison (III). Source: Own compilation according to databases

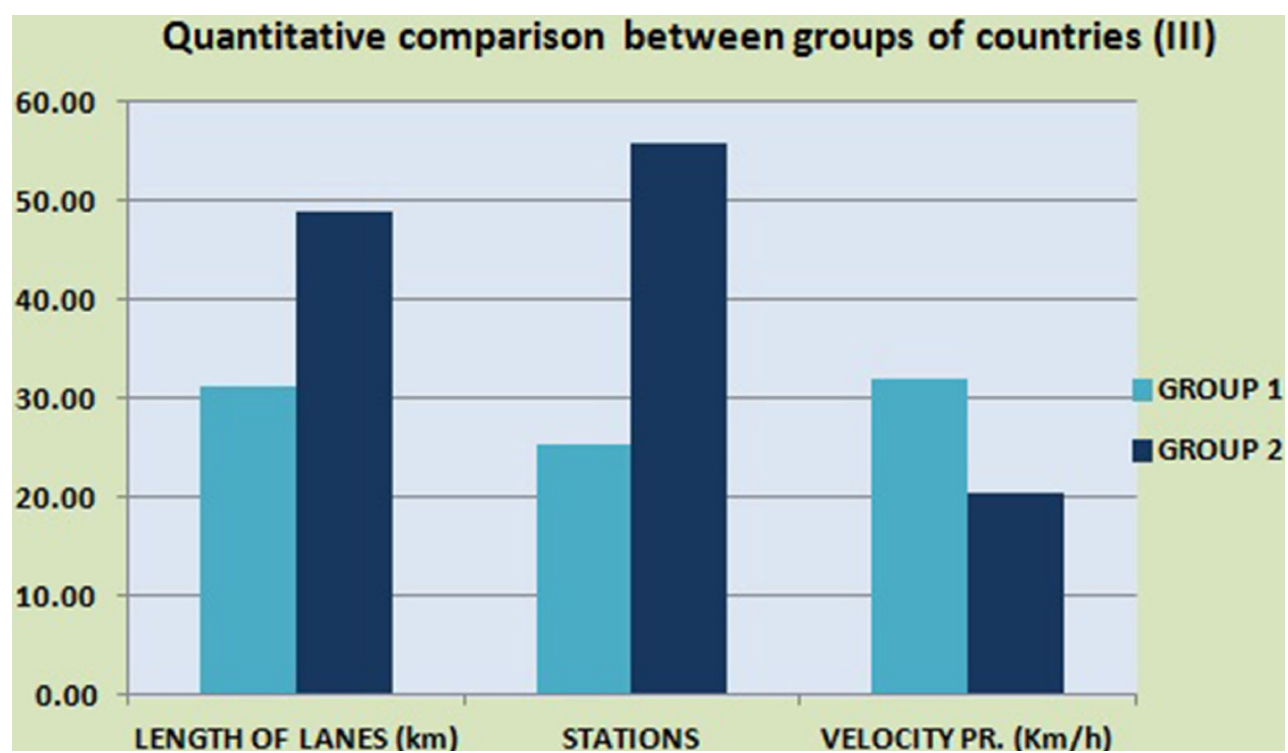




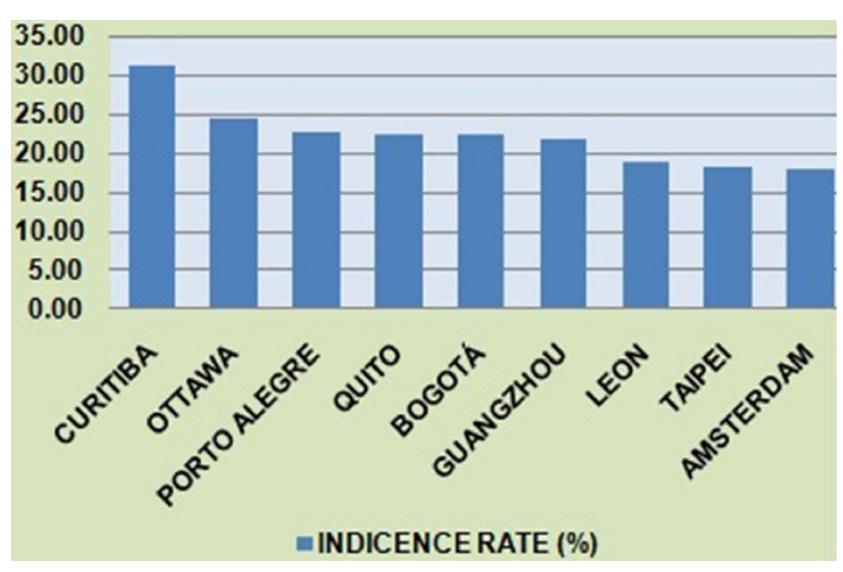

Fig. 5 BRT with most incidence on the world. Source: Own compilation
Also, if we compare the data regarding the quantity of passengers, we observe that six of the previous BRT with the highest incidence are also some with the highest number of users (Fig. 6).

The graphic above will help us to determine whether the conclusions of Currie and Delbosc [12] for Australian systems can be extended to the rest of BRT systems, as it is argued in their publication.

Such authors defend that regarding the passengers per day, the features with the highest incidence are the identity and image of the transportation system and its integration with other ways of transport. For the first case, eight of the ten cities with the greatest number of passengers have their own mark and, on the other hand, four of them have their integrated system. Then, we can observe that the identity of the mark can influence the number of passengers, whereas referring to
Fig. 6 BRT systems with the most trips per day. Source: Own compilation

Fig. 7 Quantitative comparison amongst BRT with the highest incidence. Source: Own compilation

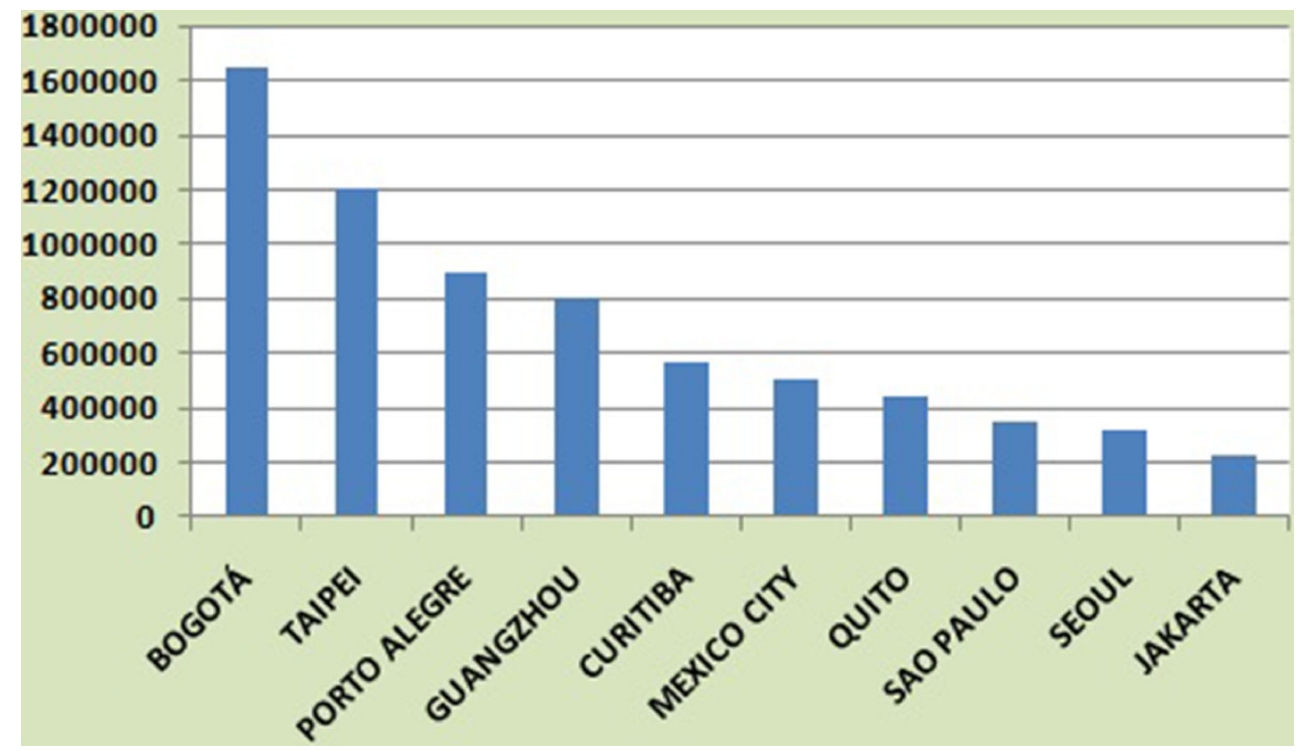


integration of systems, the results do not show a clear coincidence with the idea of Currie and Delbosc.

They conclude also that the accessibility to the system and the use of right-of-way roadways are the least influencing features for passengers, according to their mathematical analysis. In terms of comparison, it can be observed that nine of the ten systems have a level access to the bus and the whole of them have totally o partially exclusive lanes, so we can not corroborate such conclusion.

Finally, we observe that the velocity factor does not have a negative influence on the number of trips per day. The average velocity of these ten systems is $17.7 \mathrm{~km} / \mathrm{h}$, much lower than the average $27 \mathrm{~km} / \mathrm{h}$ which can be reached in European and North American cities, but this is not an obstacle to the operating of the system with a high influx of users (Fig. 7).

This last figure represents the differences amongst the ten systems with a highest incidence. It can be underlined that the average peak velocities are similar, except those for Ottawa and Amsterdam, which belong to the most developed countries group.

\section{Conclusions}

At the beginning of this paper, the BRT concept was defined and were established their main features. The analysis of the currently implemented BRT systems verifies that eight out of every ten systems have the basic theoretical features for a BRT.

After having established the features that an average massive transportation system should have, results continue being quite general, since there are great differences amongst some of the cities regarding criteria such as kilometres of lanes, quantity of users, distance between stations or infrastructure cost.

Nevertheless, comparing the different systems according to their geographical area (Africa, Asia, Europe, Oceania, South America and USA-Canada) provides some important evidences that in a quantitative approach may offer two big sets actually separated, since there are substantial differences between the massive transportation systems in more developed countries, North America, Oceania and Europe (Group 1), and in those in developing phases, South America, Asia y Africa (Group 2).

Group 1 have the technologically most advanced systems, which fit the definition of "full BRT", with fastest BRT systems but also least developed, with fewer kilometres of lanes, less stations and lower quantity of lines. However Rapid Transit Buses are more consolidated amongst the population and more developed in terms of service in the countries of the second group. The analysis of the incidence rates for the different systems indicates that the nine first systems with the highest incidence belong to the group of countries in development phases.
This could be due to the fact that in developed areas, BRT represent a complement to other ways of public transportation, whereas in the rest they are considered the transport main arteries. Moreover, in Asia and South America, another aspect that can be added to those which facilitate a good implementation of BRT is their lower cost of infrastructure.

So, the fact that some of the systems do not fulfil all the requirements may not mean that they must not be considered at the same level. Examples, such as the South American systems, actually prove that this fact is not a handicap for the right operating of them. In other words the level of fulfilment of requirements of a full BRT is not guarantee of higher success. It's necessary to understand the BRT in the context of the mobility of the city and as long as this system has to compete with other modes of transport the compliance of desirable requirements for a BRT become more essential.

Open Access This article is distributed under the terms of the Creative Commons Attribution License which permits any use, distribution, and reproduction in any medium, provided the original author(s) and the source are credited.

\section{References}

1. Thomas E (2001) Presentation at institute of transportation engineers meeting, Chicago (August)

2. Levinson H, et al. (2003) "Case studies in bus rapid transit". Bus rapid transit, Volume 1: TCRP Report 90. Washington

3. Hook W, Wright L, et al. (2007) Bus rapid transit: planning guide. Institute for Transportation and Development Policy (ITDP) $<\mathrm{http} / /$ www.itdp.org/index.php/microsite/brt_planning_guide>

4. GTZ (2006) Planificación de sistemas de bus rápido midiendo impactos, servicio al cliente y mercadeo y errores en planeación. Deutsche Gesellschaft für Technische usammenarbeit (GTZ). Presented at the 2nd international Conference of Sustainable Transportation. Mexico City

5. Kittelson Levinson H (2008) "Bus rapid transit: practitioner's guide". Transit Cooperative Research Program (TCRP), in: Report 118. $<$ http://www.community-wealth.org/_pdfs/articles-publications/tools/ tod/tool-tcrp-bus-rapid-transit.pdf $>$

6. Mojica CH, Rodríguez D (2009) Capitalization of BRT network expansions effects into prices of non-expansion areas. Transp Res Part A 43:560-571, Elsevier

7. Muñoz-Raskin R (2010) Walking accessibility to bus rapid transit: does it affect property values? The case of Bogotá Colombia. Transp Pol 17:72-84, Elsevier

8. Meirelles A (2000) A review of bus priority systems in Brazil: from bus lanes to busway transit. Smart Urban Transport Conference, Brisbane

9. China BRT. Database (2010) <http://www.chinabrt.org/defaulten.aspx>

10. Bus Rapid Transit Policy Center. Internet Database (2008) $<\mathrm{http} / /$ www.gobrt.org/db>

11. Hensher D, Golob T (2008) Bus rapid transit systems: a comparative assessment. Transp Plann, Pol, Res, Prac 35(4):501-518

12. Currie G, Delbosc A (2011) Understanding bus rapid transit route ridership drivers: an empirical study of Australian BRT systems. Transp Policy 18(5):755-764. doi:10.1016/j.tranpol.2011.03.003 